\title{
Media optimization for SHuffle T7 Escherichia coli expressing SUMO-Lispro proinsulin by response surface methodology
}

\author{
Aida Bakhshi Khalilvand ${ }^{1}$, Saeed Aminzadeh ${ }^{1 *}$, Mohammad Hossein Sanati ${ }^{2}$ and Fereidoun Mahboudi ${ }^{3}$
}

\begin{abstract}
Background: SHuffle is a suitable Escherichia coli (E. coli) strain for high yield cytoplasmic soluble expression of disulfide-bonded proteins such as Insulin due to its oxidative cytoplasmic condition and the ability to correct the arrangement of disulfide bonds. Lispro is an Insulin analog that is conventionally produced in E. coli as inclusion bodies (IBs) with prolonged production time and low recovery. Here in this study, we aimed to optimize cultivation media composition for high cell density fermentation of SHuffle T7 E. coli expressing soluble Lispro proinsulin fused to SUMO tag (SU-INS construct) to obtain high cell density fermentation.

Results: Factors including carbon and nitrogen sources, salts, metal ions, and pH were screened via Plackett-Burman design for their effectiveness on cell dry weight (CDW) as a measure of cell growth. The most significant variables of the screening experiment were Yeast extract and $\mathrm{MgCl}_{2}$ concentration, as well as $\mathrm{pH}$. Succeedingly, The Central Composite Design was utilized to further evaluate and optimize the level of significant variables. The Optimized media (OM-I) enhanced biomass by 2.3 fold in the shake flask $(2.5 \mathrm{~g} / \mathrm{L} \mathrm{CDW}$ ) that reached $6.45 \mathrm{~g} / \mathrm{L}$ ( 2.6 fold increase) when applied in batch culture fermentation. The efficacy of OM-I media for soluble expression was confirmed in both shake flask and fermentor.
\end{abstract}

Conclusion: The proposed media was suitable for high cell density fermentation of E. coli SHuffle T7 and was applicable for high yield soluble expression of Lispro proinsulin.

Keywords: CCD, E. coli, Medium composition, PBD, RSM, SHuffle

\section{Background}

Lispro, produced by Eli Lilly, is the first rapid-acting insulin analog approved for human use in 1996 [1]. This analog is suitable for post-prandial injections and overall glycemic control in insulin-dependent diabetic patients due to its accelerated action profile [2]. Lispro possesses the same pharmaceutical properties as Regular human insulin with equal molecular weight, and 1 unit of Lispro

\footnotetext{
*Correspondence: aminzade@nigeb.ac.ir

${ }^{1}$ Bioprocess Engineering Group, Institute of Industrial and Environmental

Biotechnology, National Institute of Genetic Engineering

and Biotechnology (NIGEB), Tehran, Iran

Full list of author information is available at the end of the article
}

insulin has the same blood glucose-lowering effect compared to Regular human insulin. However, they have differing pharmacodynamics and pharmacokinetics. Lispro is suitable for post-prandial administration because it embarks its action after 5-15 min after injection. Regular insulin has a slower action profile and must be administrated 30-45 min before meals $[1,3]$. Escherichia coli (E. coli) is the principal host strain for Lispro production [4]. According to the prone-to-aggregate nature of insulin molecule as a two-chained disulfide-bonded peptide, inclusion body (IB) formation in its heterologous expression in $E$. coli's reducing cytoplasmic environment is inevitable [5]. However, this poses several challenges during its production procedure. 
Various approaches are adopted to express soluble and active recombinant proteins in $E$. coli, such as applying solubilizing fusion tags and engineered host strains. One of the most efficient approaches is to utilize fusion tags such as small ubiquitin-related modifier (SUMO) [6]. Another strategy to increase soluble protein expression yield in E. coli is to employ engineered host strains with the oxidative cytoplasmic environment that is more suitable for disulfide bond formation. Origami and SHuffle strains of $E$. coli are deficient for genes responsible for cytoplasm's reducing condition, including trxB (Thioredoxin reductase) and gor (Glutathione reductase). Thus, these strains are by far more efficient for disulfide bond formation [7]. Moreover, the SHuffle strain expresses a cytoplasmic copy of disulfide bond isomerase (DsbC), a chaperone with the ability to correct the arrangement of disulfide bonds, and therefore, minimizes the formation of IBs [8].

Besides, the chemical and nutritional components of the cultivation medium can directly affect the host cell growth during target protein synthesis [9]. Several elements may control cell growth, such as Carbon (C) and Nitrogen $(\mathrm{N})$ sources, metal ions, and the medium $\mathrm{pH}$. Thus, it is essential to utilize the optimum culture composition to obtain a high yield of recombinant protein [10]. The number of contributing factors is high, and thus, it is a laborious and time-consuming task to examine the effect of each level of each variable one by one via the One-factor-at-a-time approach (OFAT). Not to mention that these factors may have dependent or either independent effects or interactive influence on responses that this strategy fails to analyze. However, the factorial approach examines all levels of all factors simultaneously to determine their independent effects and their interactions [11]. Design of experiment (DoE) is a statistical tool that examines factors and their different levels simultaneously by a reduced number of experiments via fractional factorial models such as response surface methodology (RSM) to evaluate more relevant interactions among variables [12].

We aimed to optimize culture media composition to increase the biomass of E. coli SHuffle T7 expressing SUMO-Lispro proinsulin (SU-INS) via DoE methods. The screening experiment was carried out for several culture components by Plackett-Burman Design (PBD) to evaluate their influence on SU-INS SHuffle T7 growth. Significant factors were optimized by RSM Central Composite Design (CCD) to obtain the optimum culture media composition. Afterward, optimized media was applied in the shake flask and fermentor to evaluate the soluble expression of the fusion protein and the overall reproducibility of the suggested optimal media composition.

\section{Results}

\section{Culture media optimization}

Factor screening by Plackett-Burman design

Eleven factors were evaluated for their effectiveness on bacterial growth and 20 experiments were designed by Minitab18.1.0 Software. By the end of the experiments, final cell density was measured $(\mathrm{g} / \mathrm{L} \mathrm{CDW})$ and reported in the response column of PBD (Table 1).

After data analysis, the model was significant with a $p$-value of 0.0 and an $\mathrm{R}^{2}$ of $92.96 \%$ (Table 2). Model terms including $\mathrm{pH}$, Yeast extract, $\mathrm{MgCl}_{2}, \mathrm{~N}$ source, and $\mathrm{KCl}$ concentration were effective factors with $p$-values less than 0.05 . The higher F-value of a term corresponds to the higher association of the term and the response. Pareto chart (Fig. 1) is a graphical representation of the standardized effect of each variable on response. Reference line with the value of 2.228 denotes effectiveness of factors with larger values based on significance level $(\alpha=0.05)$. According to this chart, the first 3 bars with larger values corresponding to $\mathrm{pH}$, Yeast extract, and $\mathrm{MgCl}_{2}$ concentration were selected for optimization experiment design by the CCD method of RSM. Besides, to interpret the effect of each independent variable on the Response Mean, the Main effects plot was generated by Minitab software (Fig. 2). Nearly horizontal lines correspond to insignificant variables denoting that responses are affected by none of the factor's levels. According to this plot, Tryptone was applied in optimization experiments as $\mathrm{N}$ source since there was no preference between Tryptone and Peptone. The media was supplemented by the center point level of Tryptone and $\mathrm{KCl}$. Also, the central point concentration of $\mathrm{NaCl}$ and $0.89 \mathrm{mM}$ phosphate buffer were added to the medium due to their slight refinement on the response mean. Glycerol, glucose, and $\mathrm{MgSO}_{4}$ were omitted from the model.

\section{Optimization by response surface methodology central composite design}

The Design-Expert software generated 20 experiments for RSM-based optimization of chosen model terms, including $\mathrm{pH}$, the concentration of Yeast extract, and $\mathrm{MgCl}_{2}$. Experiment runs were carried out in $50 \mathrm{~mL}$ culture containing a constant concentration of $2.5 \%$ Tryptone, $8.5 \mathrm{mM} \mathrm{NaCl}, 5 \mathrm{mM} \mathrm{KCl}$ and $0.89 \mathrm{mM}$ Phosphate buffer in addition to varied values of Yeast extract, $\mathrm{MgCl}_{2}$, and $\mathrm{pH}$ according to each design point. Corresponding results were reported in the response column of CCD as presented in Table 3.

After performing analyses by different models, the quadratic model was suggested to predict and validate the optimal condition. The model $p$-value was significant (0.0001), while its lack of fit was insignificant (0.1247) in proportion to the pure error, implying that 


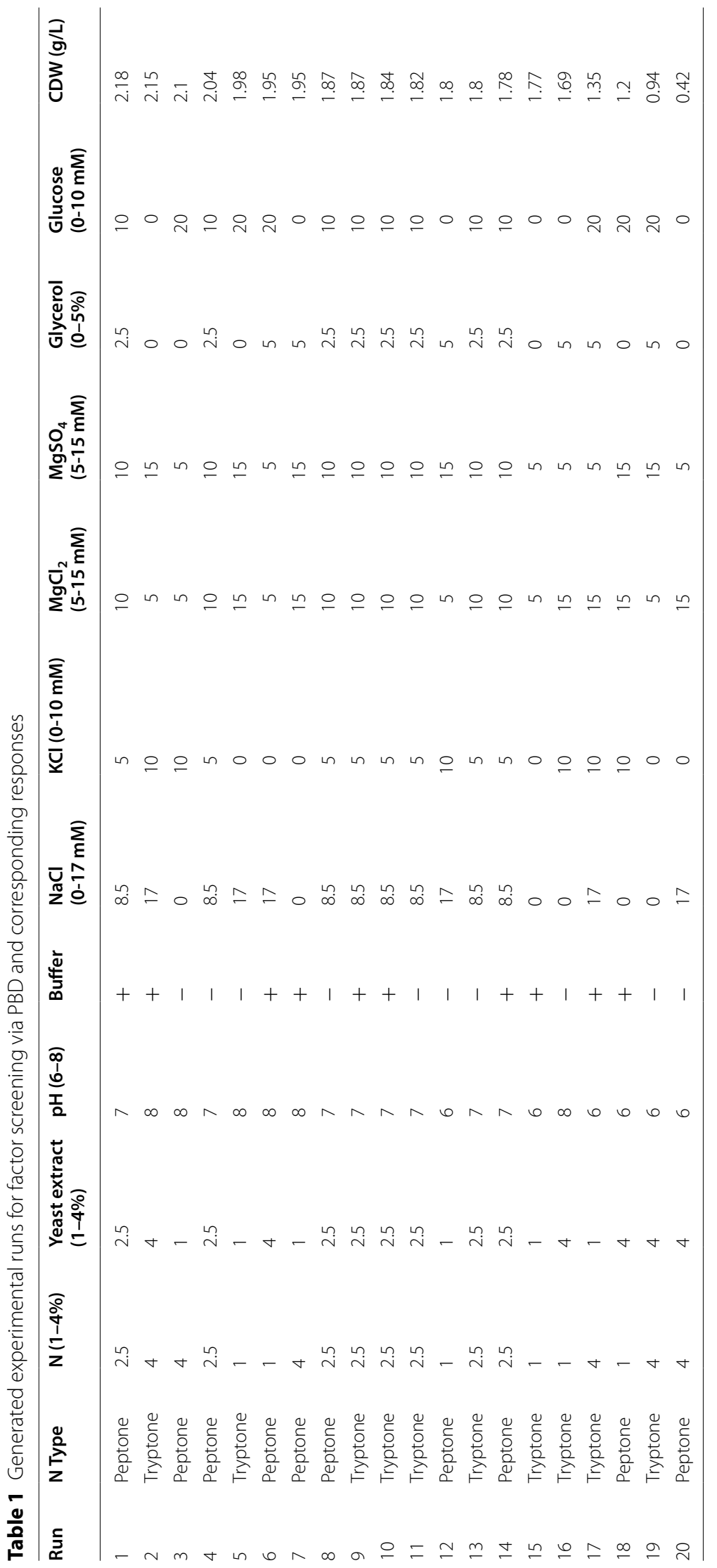


Table 2 ANOVA table of screening experiment narrating factors' significance on SHuffle T7 growth

\begin{tabular}{|c|c|c|c|c|c|}
\hline Source & Degree of freedom & $\begin{array}{l}\text { Adjusted sums of } \\
\text { squares }\end{array}$ & Adjusted mean squares & F value & $p$ value \\
\hline Model & 9 & 3.35 & 0.37 & 14.67 & 0.0 \\
\hline Linear & 8 & 2.95 & 0.37 & 14.5 & 0.0 \\
\hline N source type & 1 & 0.0 & 0.0 & 0.01 & 0.935 \\
\hline N source conc. (\%) & 1 & 0.18 & 0.18 & 7.1 & 0.024 \\
\hline Yeast extract conc. (\%) & 1 & 0.56 & 0.56 & 22.12 & 0.001 \\
\hline $\mathrm{pH}$ & 1 & 1.57 & 1.57 & 61.95 & 0.0 \\
\hline Phosphate buffer & 1 & 0.12 & 0.12 & 4.96 & 0.05 \\
\hline $\mathrm{NaCl}$ conc. $(\mathrm{mM})$ & 1 & 0.0 & 0.0 & 0.00 & 0.989 \\
\hline $\mathrm{KCl}$ conc. $(\mathrm{mM})$ & 1 & 0.14 & 0.14 & 5.38 & 0.043 \\
\hline $\mathrm{MgCl}_{2}$ conc. $(\mathrm{mM})$ & 1 & 0.37 & 0.37 & 14.48 & 0.003 \\
\hline Curvature & 1 & 0.41 & 0.41 & 16.07 & 0.002 \\
\hline Error & 10 & 0.25 & 0.02 & & \\
\hline Lack-of-fit & 6 & 0.16 & 0.03 & 1.07 & 0.498 \\
\hline Pure error & 4 & 0.1 & 0.02 & & \\
\hline Total & 19 & 3.61 & & & \\
\hline
\end{tabular}

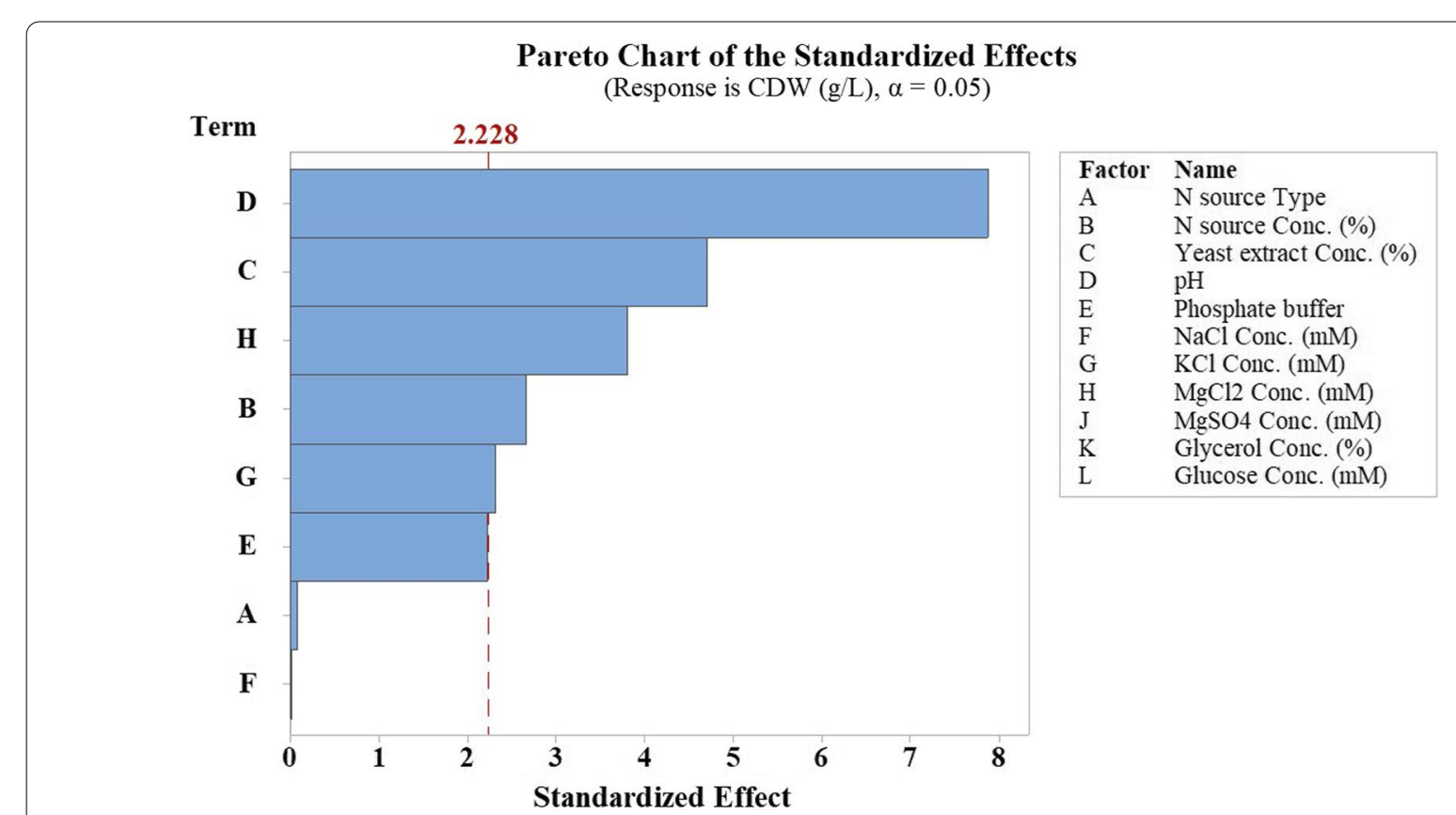

Fig. 1 Pareto chart of Standardized effects generated by PBD from screening analyses. Statistically significant factors $(p$ value $<0.05)$ are denoted with effect values larger than reference Line (2.228)

error does not have any impact on the suggested model (Table 4). The $\mathrm{R}^{2}$ value of 0.9581 , adjusted $\mathrm{R}^{2}$ of 0.9204 , and predicted $R^{2}$ of 0.7309 (Difference $<0.2$ ) indicated a reasonable fitness of the model to the experimental data and can explain $95.8 \%$ of response variations. Besides, the adequate precision value (17.8198) indicates a sufficient signal, and a smaller value of PRESS $(0.8345)$ than the total sum of squares (3.2) depicted that the model was fitted sufficiently.

The goodness of fit of the quadratic model was further evaluated by diagnostic analyses that indicated the normality of data. The Predicted vs. Actual diagnostic plots denote that the actual response values of experiment runs were in acceptable agreement with predicted response values 


\section{Main Effects Plot for CDW (g/L)}

Means

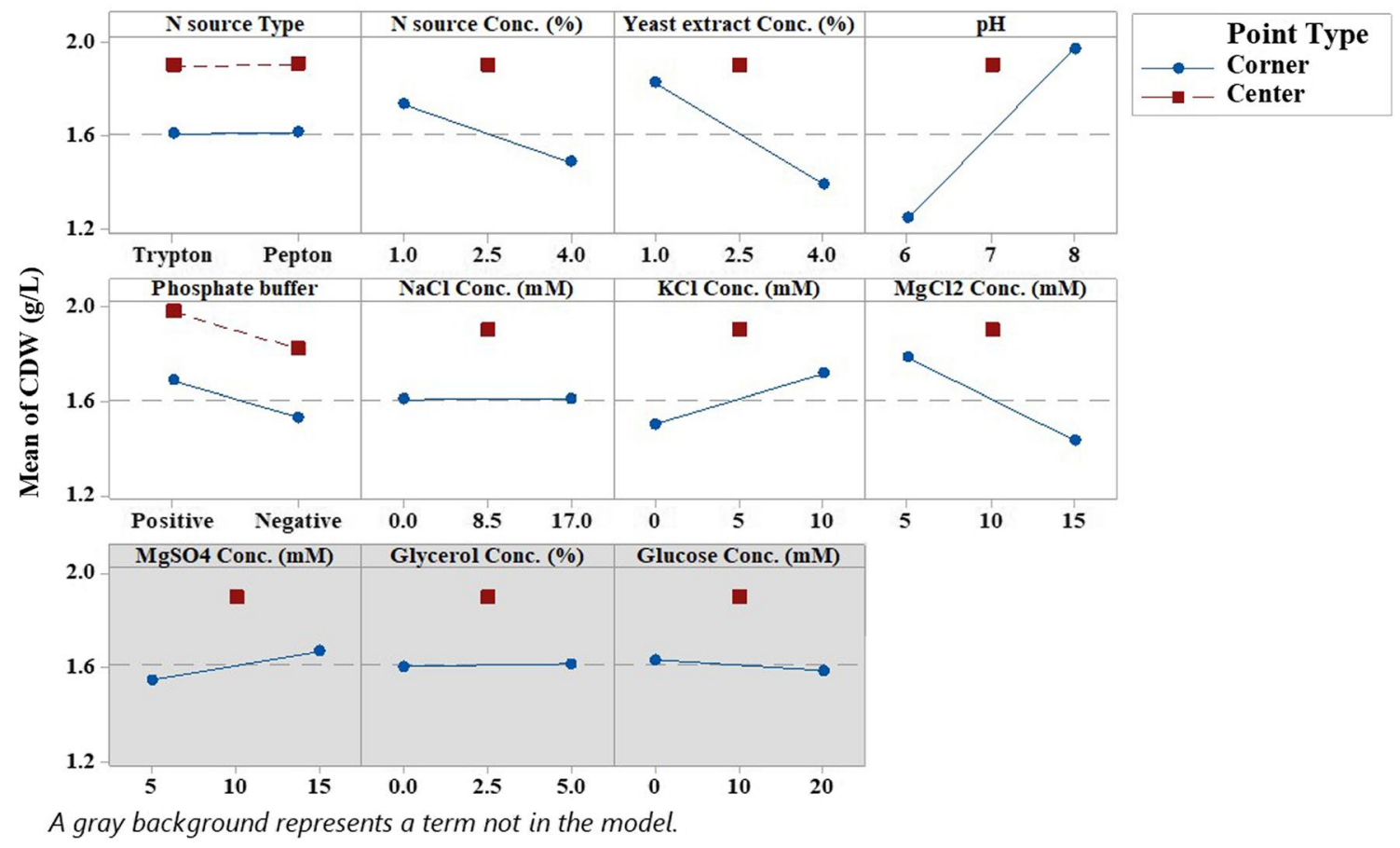

Fig. 2 Main effects plot of screening experiment (PBD). Relative effect of each independent variable level on response mean is denoted

Table 3 Generated experimental runs for factor optimization via CCD and corresponding responses

\begin{tabular}{|c|c|c|c|c|}
\hline Run & $A: p H$ & $\begin{array}{l}\text { B: Yeast } \\
\text { extract (\%) }\end{array}$ & C: $\mathrm{MgCl}_{2}(\mathrm{mM})$ & $\operatorname{CDW}(\mathrm{g} / \mathrm{L})$ \\
\hline 1 & 8 & 4 & 15 & 1.8 \\
\hline 2 & 8 & 1 & 15 & 2.2 \\
\hline 3 & 7 & 5 & 10 & 1.4 \\
\hline 4 & 8 & 1 & 5 & 1.9 \\
\hline 5 & 6 & 4 & 15 & 1.2 \\
\hline 6 & 7 & 2.5 & 10 & 2.1 \\
\hline 7 & 7 & 2.5 & 10 & 2.1 \\
\hline 8 & 8.6 & 2.5 & 10 & 2.8 \\
\hline 9 & 7 & 2.5 & 18 & 1.7 \\
\hline 10 & 5.3 & 2.5 & 10 & 1.5 \\
\hline 11 & 7 & 2.5 & 1.6 & 1.9 \\
\hline 12 & 6 & 1.0 & 15 & 1.5 \\
\hline 13 & 7 & 0 & 10 & 1.3 \\
\hline 14 & 7 & 2.5 & 10 & 2.1 \\
\hline 15 & 7 & 2.5 & 10 & 2.3 \\
\hline 16 & 7 & 2.5 & 10 & 2.2 \\
\hline 17 & 6 & 4 & 5 & 1.3 \\
\hline 18 & 6 & 1 & 5 & 1.5 \\
\hline 19 & 8 & 4 & 5 & 2.0 \\
\hline 20 & 7 & 2.5 & 10 & 2.2 \\
\hline
\end{tabular}

(Fig. 3). The compliance of the residuals with predicted values is illustrated in the Normal probability plots (Fig. 4). The Normal probability plots were linear and revealed that responses followed normal probability distribution, such that the residuals were in accordance with predicted values, and the model provided acceptable analyses.

Terms with $p$-values less than 0.05 are considered significant, and thus, can affect the response parameters; therefore, $\mathrm{A}(\mathrm{pH})$ and quadratic effect of terms $\mathrm{B}$ (Yeast extract) and $\mathrm{C}\left(\mathrm{MgCl}_{2}\right),\left(\mathrm{B}^{2}\right.$ and $\left.\mathrm{C}^{2}\right)$ were significant model terms. Based on the quadratic model, the $3 \mathrm{D}$ and contour plots were generated (Fig. 5). According to Fig. 5, the highest response was accomplished when the media was supplemented by medium levels of Yeast extract (2.5\%) and $\mathrm{MgCl}_{2}(10 \mathrm{mM})$ coupled with maximum $\mathrm{pH}(8)$.

The equation in terms of actual factors was achieved from the quadratic model depicting the mathematical model for biomass production with culture optimization process: 
Table 4 ANOVA table of culture media optimization for SHuffle T7 growth (Quadratic model)

\begin{tabular}{llllcr}
\hline Source & Sum of Squares & $\boldsymbol{d f}$ & Mean Square & F-value & $\boldsymbol{p}$ value \\
\hline Model & 3.06 & 9 & 0.3404 & 25.43 & $<0.0001$ \\
A-pH & 1.47 & 1 & 1.47 & 109.80 & $<0.0001$ \\
B-Yeast Extract & 0.0353 & 1 & 0.0353 & 2.63 & 0.1356 \\
C-MgCl ${ }_{2}$ & 0.0070 & 1 & 0.0070 & 0.5258 & 0.4850 \\
$\mathrm{AB}$ & 0.0002 & 1 & 0.0002 & 0.0187 & 0.8940 \\
$\mathrm{AC}$ & 0.0051 & 1 & 0.0051 & 0.3846 & 0.5490 \\
$\mathrm{BC}$ & 0.0586 & 1 & 0.0586 & 4.38 & 0.0629 \\
$\mathrm{~A}^{2}$ & 0.0120 & 1 & 0.0120 & 0.8927 & 0.3670 \\
$\mathrm{~B}^{2}$ & 1.31 & 1 & 1.31 & 98.07 & $<0.0001$ \\
$\mathrm{C}^{2}$ & 0.2779 & 1 & 0.2779 & 20.76 & 0.0010 \\
Residual & 0.1339 & 10 & 0.0134 & 3.03 & 0.1247 \\
Lack of Fit & 0.1006 & 5 & 0.0201 & & Not significant \\
Pure Error & 0.0332 & 5 & 0.0066 & & \\
Cor Total & 3.20 & 19 & & & \\
\hline
\end{tabular}

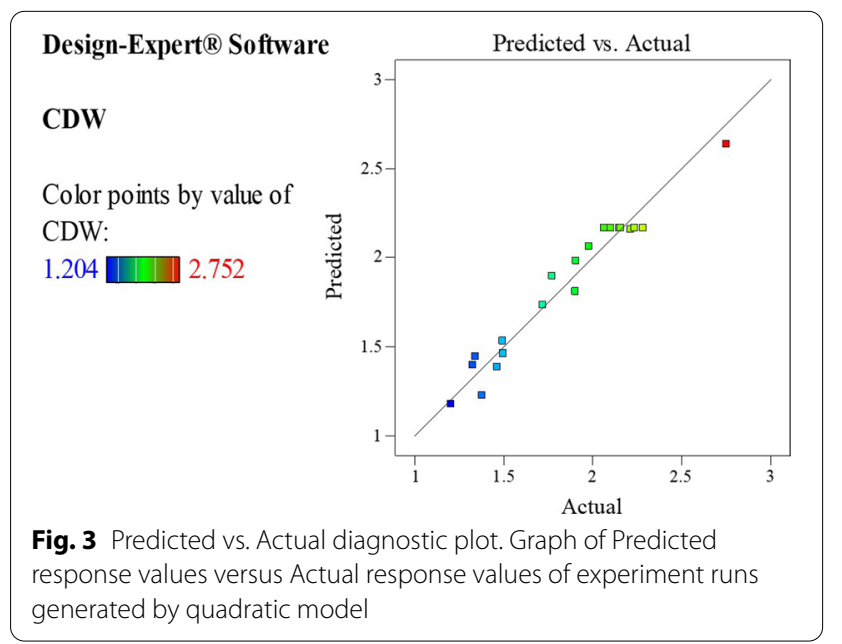

$$
\begin{aligned}
C D W\left(\frac{g}{L}\right)= & -2.68893+0.67111 \mathrm{pH}+0.736996 \text { Yeast Extract } \\
& +0.099864 \mathrm{MgCl}_{2}+0.003752 \mathrm{pH} * \text { Yeast Extract } \\
& +0.005074 \mathrm{pH} * \mathrm{MgCl}_{2}-0.011486 \text { Yeast Extract } * \mathrm{MgCl}_{2} \\
& -0.028798 \mathrm{pH}^{2}-0.135958 \text { Yeast Extract }{ }^{2}-0.00555 \mathrm{MgCl}_{2}^{2}
\end{aligned}
$$

The Design-Expert software utilizes the obtained equation for point prediction according to chosen circumstances for each model term and response. Optimization was validated by examining three of the software suggestions with the highest desirability (Table 5 ). All resulted in an approximately same cell density of $2.5 \mathrm{~g} / \mathrm{L}$.

The optimum condition for maximum growth determined to be $2.5 \%$ Tryptone, $2.5 \%$ yeast extract, $10 \mathrm{mM}$ $\mathrm{MgCl}_{2}, 5 \mathrm{mM} \mathrm{KCl}, 8.5 \mathrm{mM} \mathrm{NaCl}$ and $\mathrm{pH}$ 8. The OM-I media was compared to LB media that resulted in more

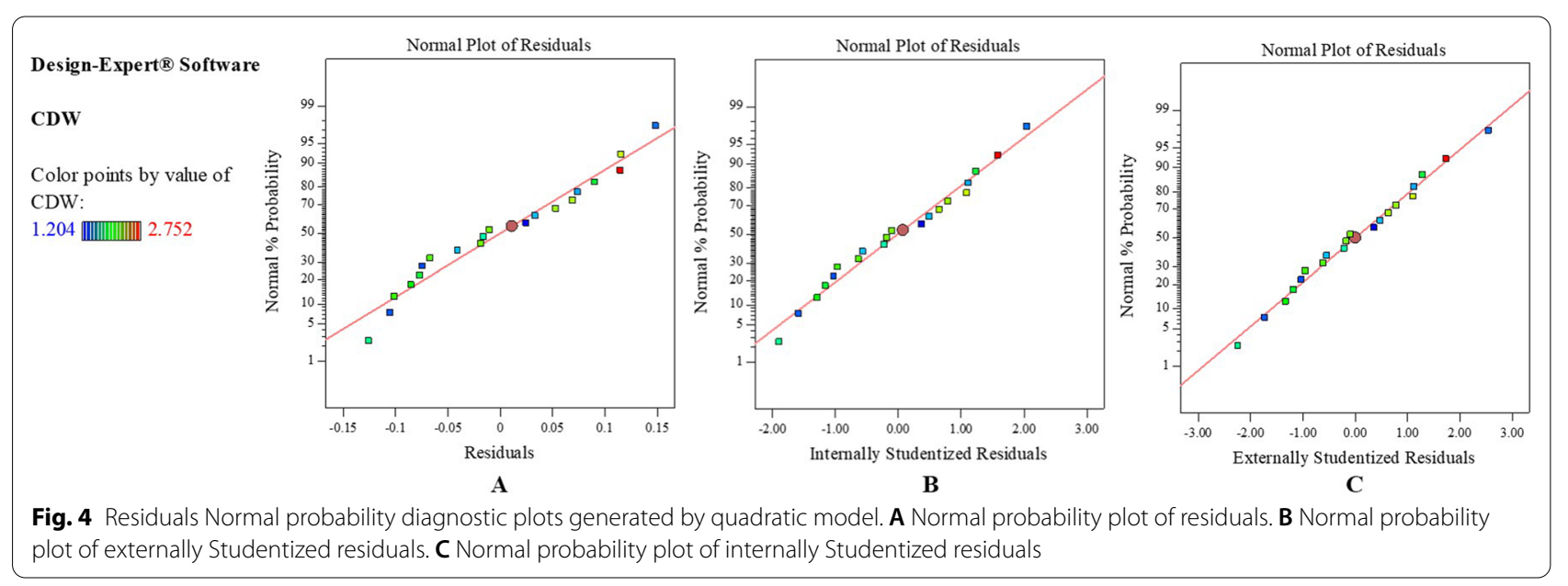




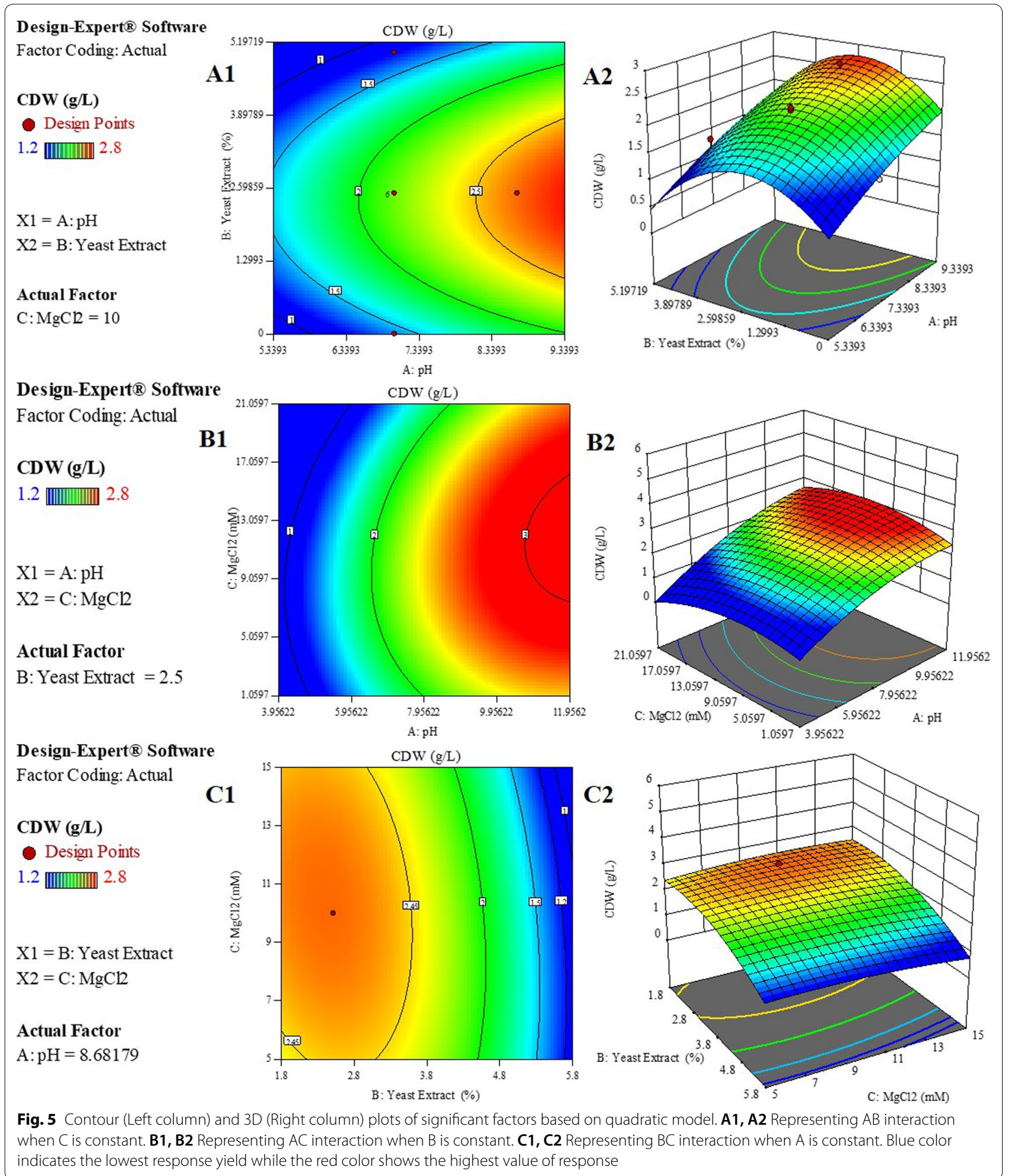


Table 5 Predicted optimal conditions for maximum Biomass production

\begin{tabular}{llllll}
\hline No & $\mathbf{p H}$ & $\begin{array}{l}\text { Yeast extract } \\
\text { concentration } \\
(\%)\end{array}$ & $\begin{array}{l}\mathbf{M g C l}_{2} \\
\text { concentration } \\
(\mathbf{m M})\end{array}$ & $\mathbf{C D W}(\mathbf{g} / \mathbf{L})$ & Desirability \\
\hline 1 & 8 & 2.5 & 10 & 2.468 & 0.963 \\
2 & 8 & 2.5 & 9.5 & 2.465 & 0.963 \\
3 & 8 & 2.4 & 10.2 & 2.468 & 0.963 \\
\hline
\end{tabular}
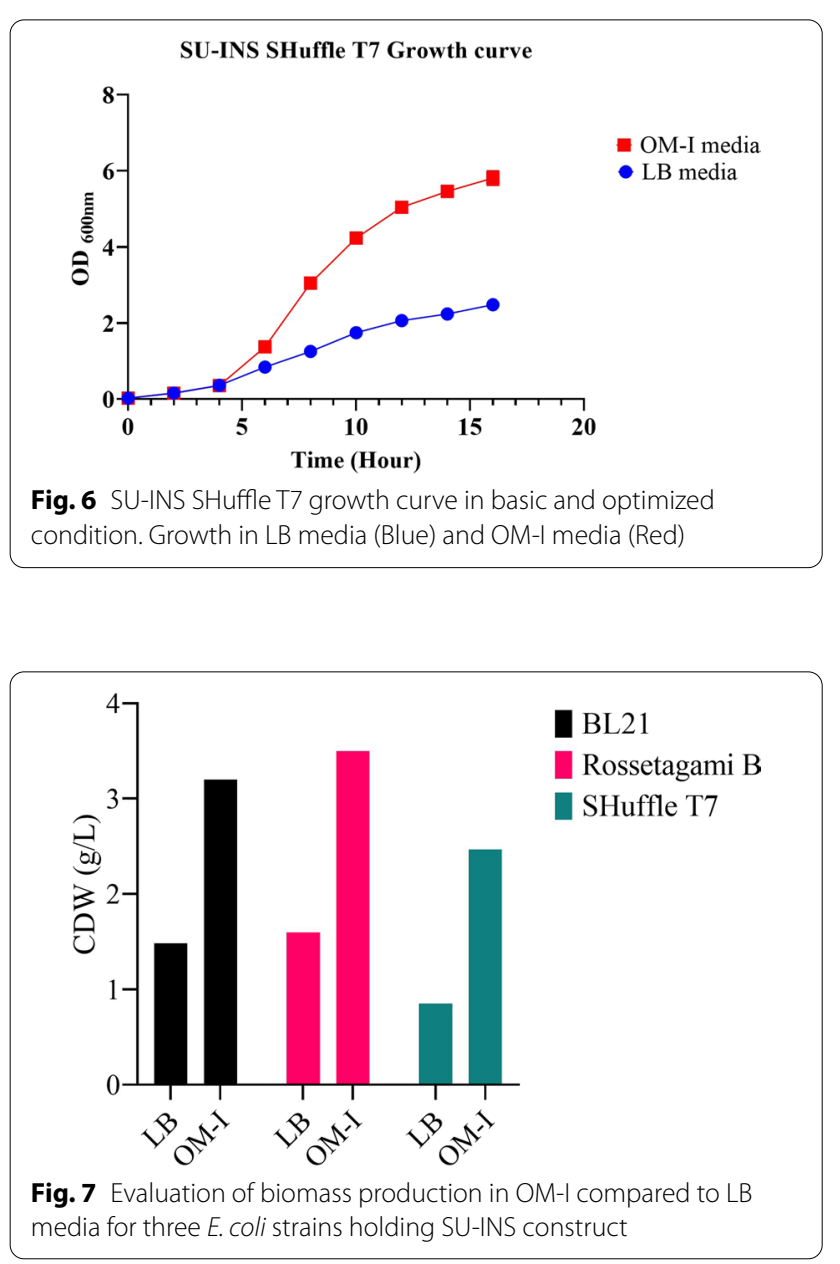

than 2.3-fold higher biomass with $\mathrm{OD}_{600}$ of approximately 5.8 (corresponding to $2.5 \mathrm{~g} / \mathrm{L} \mathrm{CDW)} \mathrm{compared} \mathrm{to}$ $\mathrm{LB}$ media $\left(\mathrm{OD}_{600}\right.$ of 2.5 or $\left.1.08 \mathrm{~g} / \mathrm{L} \mathrm{CDW}\right)$. The growth curve of SHuffle T7 culture in OM-I media was graphed against basic conditions (Fig. 6).

OM-I was applicable for other $E$. coli strains including BL21 (DE3) and Rossetagami B holding similar gene construct (SU-INS). More than twofold biomass was obtained when cells were cultivated in OM-I media compared to LB media (Fig. 7).

\section{Evaluation of optimal points for soluble expression in shake} flask

The soluble expression of the POI was evaluated in OM-I media compared to LB media in triplicates to assess the effect of media ingredient optimization on the soluble expression of the fusion protein. The results of experiments were visualized by Coomassie-stained SDS-PAGE that revealed competitively higher soluble POI produced in OM-I media (Fig. 8a).

\section{Final product identity and bioactivity assessment}

To evaluate the feasibility of bioactive Lispro insulin production from expressed fusion protein, the POI was purified, modified, and undergone proteolytic cleavage. His-tagged POI was isolated by Immobilized metal affinity chromatography (IMAC) via Nickel sepharose resin (Fig. 8b) [13].

The Purified POI was successfully converted to bioactive insulin Lispro and retained its solubility after the tag and C-peptide removal. The produced Lispro was identical to its commercially available analog considering electrophoretic mobility, LC-MS/MS, Circular Dichroism (CD), HPLC, and bioactivity analyses (Data not shown) [13].

\section{Evaluation of OM-I media in fermentor (Batch culture)}

The large-scale applicability of optimal media was assessed in a $5 \mathrm{~L}$ volume fermentor vessel containing 3 L OM-I media. The final $\mathrm{OD}_{600}$ of 15 was achieved after $15 \mathrm{~h}$ of inoculation ( $8 \mathrm{~h}$ after induction), and bacterial culture went in the stationary phase at this point (Fig. 9a). Approximately $86 \mathrm{~g}$ bacterial wet weight corresponding to $6.45 \mathrm{~g} / \mathrm{L} \mathrm{CDW}$ was obtained after harvest. The bacteria pellet was resuspended in $35 \mathrm{~mL}$ of the Lysis buffer, and the soluble lysate was collected. SDS-PAGE results revealed a considerably high concentration of soluble POI obtained from fermentor culture (Fig. 9b) (Additional file 1; Fig. S1).

\section{Discussion}

E. coli is one of the most employed hosts for recombinant protein production due to its advantageous characteristics such as rapid growth, easier genetic manipulations, and high yield recombinant protein synthesis rates [14]. $E$. coli was the first expression host used for manufacturing human insulin in 1982 [15]. However, due to its prone-to-aggregate structure, insulin expression in E. coli leads to IB formation [5]. We used the SUMO solubilizing tag and SHuffle T7 strain (SU-INS SHuffle T7 clone) in our previous work to prevent IB formation. Here in this study, we intended to optimize culture media composition to improve SU-INS SHuffle T7 growth rate and biomass yield. 


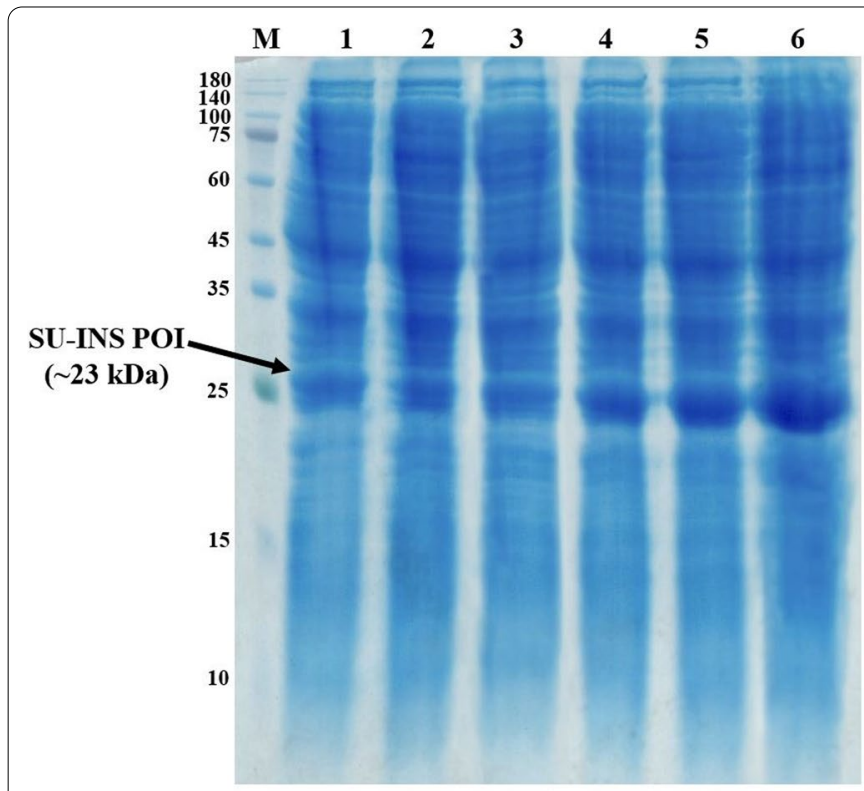

A

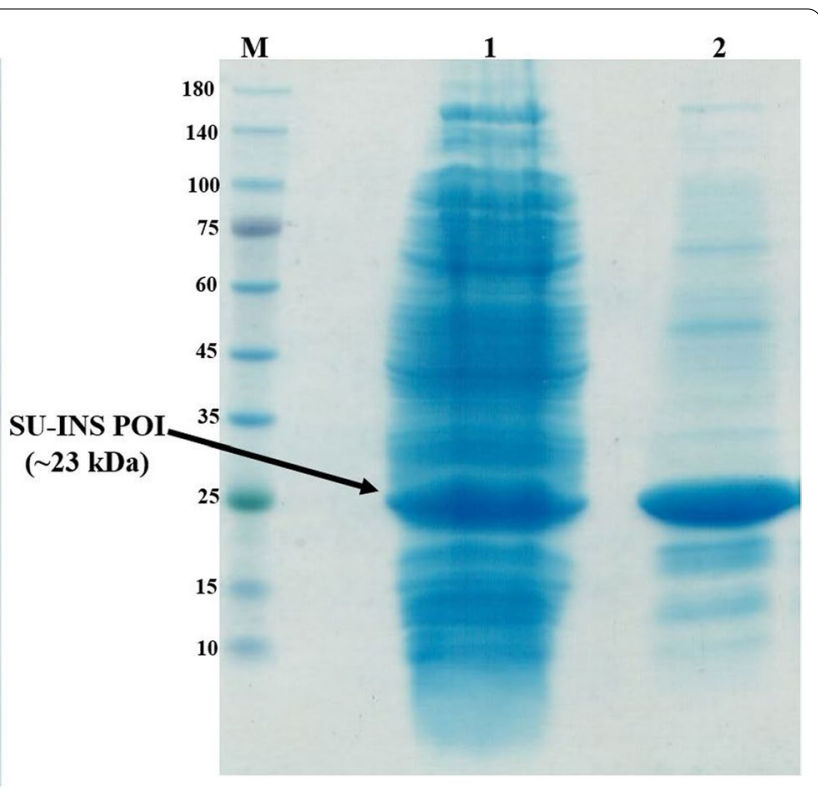

B

Fig. 8 POI soluble expression and Purification. Coomassie stained 12\% SDS-PAGE: A POI soluble expression in LB and OM-I media. M. Protein Marker. 1-3: POI soluble expression in LB media. 4-6: POI soluble expression in OM-I media. B SU-INS POI IMAC purification. M. Protein Ladder. 1: Cell lysate supernatant (Unpurified), 2: Purified POI

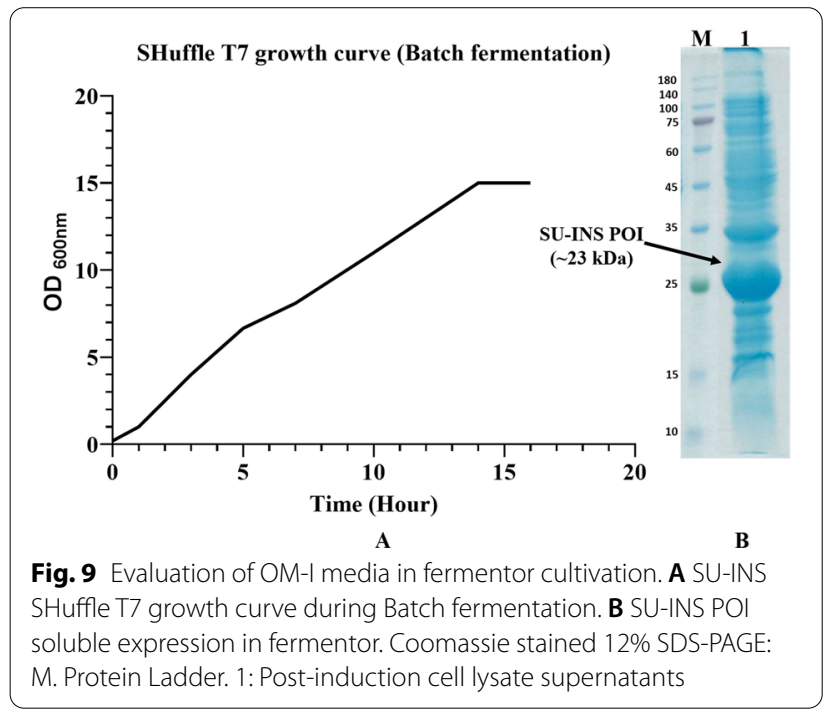

The bacterial growth rate, similar to other natural processes, may have countless contributing parameters. Identification and optimization of these factors pose several challenges concerning expenditure and overall economics [16]. Considering this, DoE is a powerful tool in statistical bioprocess optimization that can obtain elevated results with reduced time and effort [17]. Several studies have utilized DoE methods to improve the yield of recombinant protein expression in E. coli through culture media optimization. Table 6 summarizes some of the previous similar studies considering product type, design method, evaluated factors, and the optimization outcome. L-Asparaginase, Phytase, Streptokinase, and Reteplase are some of the proteins expressed in E. coli and undergone DoE based culture media optimization that led to enhanced production yield. Based on reviewed literature (Table 6), numerous variables may affect bacterial growth rate and biomass production. The type and concentration of $\mathrm{C}$ and $\mathrm{N}$ source, $\mathrm{pH}$, and trace elements are some of the most studied variables.

In this study, PBD was used to screen the effect of eleven factors on cell growth including, the concentration of various $\mathrm{N}$ and $\mathrm{C}$ sources, salts, metal ions, $\mathrm{pH}$, and the buffering system. Among mentioned factors, $\mathrm{pH}$, Yeast extract, and $\mathrm{MgCl}_{2}$ concentration had the most influence on cell growth and, thus, were chosen for further optimization by RSM Central Composition Design. To a lesser extent, the concentration of $\mathrm{N}$ source and $\mathrm{KCl}$ was also significant such that their central point level led to a higher response (Fig. 2). Thus, their mid-point concentration was used in the culture media. Additionally, the presence of $0.89 \mathrm{mM}$ Phosphate buffer was beneficial for cell growth; similarly, the central point value of $\mathrm{NaCl}$ corresponded to a high response mean, thus were used in culture media. Model terms with insignificant $p$-values, such as $\mathrm{MgSO}_{4}$, glycerol, and glucose concentrations, as 
Table 6 Literature review on DoE-based optimization of E. coli culture condition

\begin{tabular}{|c|c|c|c|c|c|}
\hline Host Organism & Product & Design & Studied factors & Product increase & Reference \\
\hline E. coli SHuffle T7 & Biomass (SU-INS) & PBD, CCD & $\begin{array}{l}\text { C, N sources, inorganic salts, } \\
\mathrm{pH}\end{array}$ & $\begin{array}{l}2.3 X \text { (shake flask), } 5.9 X \\
\text { (fermentor) }\end{array}$ & Present study \\
\hline E. coli BL21 (DE3) & Phytase & CCD & C, N sources, salt & $1.2 x$ & {$[18]$} \\
\hline E. coli (ATCC no. 11303) & L-Asparaginase & OFAT, CCD & $\begin{array}{l}\text { C, N sources, ions, inoculum } \\
\text { age and size }\end{array}$ & $10 x$ & {$[19]$} \\
\hline E. coli BL21 (DE3) & L-Asparaginase II & FFD, CCFD & C, N sources, ions & NA & {$[20]$} \\
\hline E. coli BL21 (DE3) & Streptokinase & $\mathrm{PBD}, \mathrm{CCD}$ & C, N sources, ions & $7 X$ & {$[21]$} \\
\hline E. coli & $\begin{array}{l}\text { Dihydrolipohyl Dehydro- } \\
\text { genase }\end{array}$ & CCFD & $\begin{array}{l}\text { C, N sources, inorganic salts, } \\
\mathrm{pH}\end{array}$ & $\begin{array}{l}1.2 X \text { (shake flask), } 1.7 X \\
\text { (fermentor) }\end{array}$ & {$[22]$} \\
\hline E. coli DH5a & $\begin{array}{l}\text { Rheumatoid arthritis DNA } \\
\text { vaccine }\end{array}$ & OFAT, PBD, BBD & $\begin{array}{l}\text { C, N sources, salts, trace } \\
\text { elements, pH, inoculum size, } \\
\text { temperature }\end{array}$ & $51.9 \%$ & {$[23]$} \\
\hline E. coli MET-3 & L-Methionine & PBD, BBD & C, N sources, salts & $\begin{array}{l}1.5 \mathrm{X} \text { (shake flask), } 6.4 \mathrm{X} \\
\text { (fermentor) }\end{array}$ & {$[24]$} \\
\hline E. coli BL21 (DE3) & Reteplase & BBD & Temperature, Agitation, pH & $2 X$ & {$[25]$} \\
\hline E. coli $\Delta$ waaf & Colanic acid & FFD, CCD & C, N sources, inorganic salts & $12 X$ & {$[26]$} \\
\hline E. coli BL21 (DE3) & $\begin{array}{l}\gamma \text {-cyclodextrin glycosyltrans- } \\
\text { ferase }\end{array}$ & $\begin{array}{l}\text { OFAT, PBD, Steep- } \\
\text { est ascent path, } \\
\text { BBD }\end{array}$ & $\begin{array}{l}\text { C, N sources, inorganic salts, } \\
\mathrm{pH}\end{array}$ & $2.83 X$ & {$[27]$} \\
\hline
\end{tabular}

well as the $\mathrm{N}$ source type, were omitted from media in CCD experiments.

According to RSM results, $\mathrm{pH}$ was the most influential factor as though its highest level correlated with higher cell growth and biomass. Our result was in agreement with other work which reported that a $\mathrm{pH}$ increase could improve the level of Reteplase production in E. coli [25]. Avoiding cellular stresses such as the metabolic burden of acidification and proteases during the synthesis of recombinant proteins can contribute enormously to overall cell growth [10]. C source metabolism leads to the accumulation of acetate and acidic by-products in the culture medium that can reduce cell growth and recombinant protein production. In this case, the addition of Yeast extract and Tryptone can prevent medium acidification due to the high amount of ammonia produced during their metabolism [10, 28]. Likewise, maintaining $\mathrm{pH} 8$ in the culture medium ameliorates the acetate stress in $E$. coli cultivation [29]. OM-I is a suitable media by being rich in Yeast extract and Tryptone, in addition to the presence of a strong buffer ( $\mathrm{pH} 8$ ) that evokes elevated cell growth and delayed entrance to the death phase. The proposed media enhanced $E$. coli SHuffle T7 biomass by 2.3 fold in shake flask which further increased by an extra 2.6 fold in batch culture fermentor. OM-I is a suitable media for high cell density fermentation of other E. coli strains such as Rossetagami B and BL21 (DE3).

\section{Conclusion}

The optimum cultivation medium composition was demonstrated for SU-INS SHuffle T7 clone expressing SUMO-Lispro proinsulin fusion protein. The optimal media (OM-I media) was validated and compared to basic media (LB media), which led to approximately 2.3 fold more biomass. The OM-I is an efficient media for the SU-INS fusion protein production in shake flask which is reproducible in large-scale fermentation.

\section{Methods}

Microorganism, culture media, chemicals and software

E. coli SHuffle T7 strain (purchased from NEB) transformed by pET21a + vector containing SU-INS construct (GenBank accession no. MW291010) was used in this study. SU-INS construct contained N-terminal 6XHis-tag and SUMO fusion tag. Luria- Bertani (LB) media used as the basic culture media for primary evaluation of growth and soluble expression of SU-INS SHuffle T7 clone. BL21 and Rossetagami B strains (purchased from Novagen) were applied as alternative host strains to assess the applicability of optimized media. Chemical ingredients were purchased from either Merck or Sigma. Protein weight marker (PS-103) was supplied from Jena. Minitab18.1.0 software (Minitab Inc., State College, PA, USA) was applied for screening experiments. Optimization experiments were designed and analyzed by DesignExpert 11.0.0 software (Stat-Ease, Inc., Minneapolis, MN, USA). 


\section{Seed preparation for DoE}

The newly transformed frozen stock of SU-INS SHuffle T7 was cultured on a streak plate and was incubated at $30{ }^{\circ} \mathrm{C}$ for $16 \mathrm{~h}$ to obtain single colonies. Then, $10 \mathrm{~mL} \mathrm{LB}$ media in a $50 \mathrm{~mL}$ shake flask was inoculated by a single colony and incubated overnight at $30{ }^{\circ} \mathrm{C}$ and $180 \mathrm{rpm}$ (revolutions per minute) shake until reaching the $\mathrm{OD}_{600}$ (Optical Density at $\lambda=600 \mathrm{~nm}$ ) of 2. Afterward, seed culture was scaled up in a $500 \mathrm{~mL}$ volume shake flask containing $100 \mathrm{~mL} \mathrm{LB}$ media by inoculating $2 \mathrm{~mL}$ of preculture and incubated at $30{ }^{\circ} \mathrm{C}$ with $180 \mathrm{rpm}$ shaking. After reaching the $\mathrm{OD}_{600}$ of 2 bacterial culture was centrifuged at $2500 \mathrm{xg}$ for $5 \mathrm{~min}$, and then cells were resuspended in $20 \mathrm{~mL}$ WFI (Water for injection) immediately before use.

\section{Cell dry weight measurement}

Cell dry weight per 1 Liter of culture media (g/L CDW) was measured for $20 \mathrm{~mL}$ culture volume according to the method described by [30]. $\mathrm{OD}_{600}$ to CDW conversion coefficient was approximately $0.43 \mathrm{~g}$. CDW was calculated via the multiplication of $\mathrm{OD}_{600}$ values by 0.43 .

\section{Optimization of cultivation medium}

Firstly, PBD screened the effectiveness of various factors. Then, the CCD method of RSM optimized the level of influential variables. All experiments were carried out in $250 \mathrm{~mL}$ volume shake flasks containing $50 \mathrm{~mL}$ culture media. Media was prepared according to each designed point and inoculated by seed culture to the initial $\mathrm{OD}_{600}$ of 0.1 and then incubated at $30^{\circ} \mathrm{C}$ with $180 \mathrm{rpm}$ shake for $16 \mathrm{~h}$. The $\mathrm{OD}_{600}$ of culture was used for measuring bacterial growth via Plate reader (Biotek SynergyHTX, USA). Then, CDW (g/L) was calculated as the response of experiments.

\section{Factor screening via Plackett-Burman factorial design}

Eleven factors examined in the screening experiment included the concentration of various $\mathrm{N}$ and $\mathrm{C}$ sources, $\mathrm{pH}$, presence of $0.89 \mathrm{mM}$ phosphate buffer, and the concentration of salts and metal ions. Twenty experiments, including eight central points (Table 1 ) designed by twolevel Plackett-Burman factorial design via Minitab software. After performing experiments, responses were analyzed statistically. Model validation parameters and variable significance values were reported in ANOVA (Analysis of variance) and fit statistic tables. Significant variables ( $p$-values $<0.05$ ) were selected based on the ANOVA table, Pareto chart of standardized effects, and main effects plot of response means.

\section{Factor optimization via response surface methodology}

Based on PBD results, three of the most significant factors were selected for further optimization by 5-level CCD in Design-Expert software resulted in twenty experimental runs, including six central points (Table. 3 ). To prepare culture media for each run, the specified composition of model terms (chosen factors) were used according to designed points. Besides, constant values of other media components that were not in the model were supplemented in the media according to the Main effects plots of PBD. The concentration that corresponded to the highest response for less significant variables and -1 level of insignificant factors were supplied (Fig. 2). Following the execution of experiments, responses were analyzed via different models. The best model was selected based on model validation parameters reported in the ANOVA table and fit statistic tables in addition to diagnostic analysis. Design-Expert software generated the diagnostic reports and plots, including the Predicted vs. Actual diagnostic plot and Normal Probability plots of Residuals. The effect of each significant independent and dependent variable on response was reported graphically via contour and 3D plots. Finally, Design-Expert software generated predictions about optimal points based on the obtained regression equation. Predicted design points with the highest desirability were examined and compared to the basic condition (Cultured in LB media) in triplicates. The suggested optimal media was named OM-I media.OM-I media was examined for other E. coli strains, including BL21 (DE3) and Rossetagami B holding SU-INS construct compared to LB media and their biomass was measured.

\section{Soluble expression analysis}

The expression of SUMO-Lispro proinsulin fusion protein was evaluated in OM-I media compared to LB media in triplicates to assess the efficacy of optimal media to express the protein of interest (POI) in soluble form. The experiments were carried out in $250 \mathrm{~mL}$ volume shake flasks containing $50 \mathrm{~mL}$ of either OM-I or LB media. Each shake flask was inoculated by seed culture to initial $\mathrm{OD}_{600}$ of 0.1 and then incubated at $30^{\circ} \mathrm{C}$ with $180 \mathrm{rpm}$ agitation until reaching the $\mathrm{OD}_{600}$ of 0.6 . Then, cultures were induced by $0.4 \mathrm{mM}$ IPTG and were incubated at $30^{\circ} \mathrm{C}$ for $8 \mathrm{~h}$. Cultures were centrifuged at $8000 \mathrm{xg}$ for $20 \mathrm{~min}$. The obtained pellet of each experiment was resuspended in $5 \mathrm{~mL}$ Lysis buffer (50 mM NaH $\mathrm{PO}_{4}, 300 \mathrm{mM} \mathrm{NaCl}, 10 \%$ Glycerol, $1 \mathrm{mM}$ PMSF, pH 8), sonicated (10 bursts of $30 \mathrm{~s}$ followed by 1-min rest after each interval), and centrifuged at $15000 x \mathrm{xg}$ for $30 \mathrm{~min}$. The supernatant of each experiment was collected. Soluble expression of POI was assessed by $12 \%$ SDS-PAGE. 


\section{POI purification and bioconversion}

The attainability of properly folded Lispro insulin was assessed through POI isolation and proteolytic conversion according to protocols explained in our submitted manuscript [13]. Purification of His-tagged POI was achieved through Nickel sepharose resin. Purification efficiency was assessed by SDS-PAGE and visualized by Coomassie blue staining. POI was converted to Lispro insulin by Trypsin and Carboxypeptidase B cleavage. Lispro was purified by Source $^{\mathrm{TM}}$ 30RPC resin. The identity of the final product was evaluated by electrophoresis, LCMS/MS, RP-HPLC, CD analyses, and bioactivity compared to commercial Lispro insulin as reference [13].

\section{Fermentor cultivation and expression}

Batch culture fermentation was carried out to assess the reproducibility of optimized culture media for larger scales. Fermentor seed pre-culture was prepared in $15 \mathrm{~mL}$ OM-I media containing $50 \mu \mathrm{g} / \mathrm{mL}$ Ampicillin and incubated at $30{ }^{\circ} \mathrm{C}$ until reaching the $\mathrm{OD}_{600}$ of 2 . Afterward, pre-culture was scaled up in a $2 \mathrm{~L}$ shake flask containing $300 \mathrm{~mL}$ OM-I media generating the initial $\mathrm{OD}_{600}$ of 0.1 . Then, seed culture was incubated at $30{ }^{\circ} \mathrm{C}$ with $180 \mathrm{rpm}$ agitation until reaching the $\mathrm{OD}_{600}$ of 2 and was used as fermenter seed. 2.7 L OM-I media was prepared and applied into a $5 \mathrm{~L}$ fermentation vessel (New Brunswick Scientific Co., USA). $300 \mathrm{~mL}$ seed was added to the fermentor vessel to obtain the initial $\mathrm{OD}_{600}$ of 0.2 . Fermentation was carried out at $30^{\circ} \mathrm{C}$, and the acidity of culture was maintained at $\mathrm{pH} 8$ by Ammonia solution. DO (Dissolved oxygen) was set constant at 37\%, and aeration was set at $1 \mathrm{vvm}$ (Volume of air per unit of medium per unit of time $(\mathrm{L} / \mathrm{L} / \mathrm{m}))$, and agitation was controlled by DO changes to a maximum of 800 RPM. Samples were collected each one hour until reaching the $\mathrm{OD}_{600}$ of 6 . At this point, the culture was induced by $0.4 \mathrm{mM}$ IPTG. After induction, growth was monitored hourly until the beginning of the stationary phase. Bacterial culture was harvested by centrifugation at $4500 x g$ for $45 \mathrm{~min}$. Bacterial pellet resuspended in Lysis buffer $(5 \mathrm{~mL} / \mathrm{g}$ bacterial wet weight) and homogenized at $600 \mathrm{psi}$ twice. Then, the homogenized cell lysate was centrifuged, and its supernatant was collected. Soluble expression of POI was assessed by $12 \%$ SDS-PAGE.

\footnotetext{
Abbreviations

IB: Inclusion body; E. coli: Escherichia coli; RSM: Response surface methodology; PBD: Plackett-Burman design; CCD: Central composite design; SUMO: Small ubiquitin-related modifier; trxB: Thioredoxin reductase gene; gor: Glutathione reductase gene; DsbC: Disulfide bond isomerase; OFAT: One-factor-at-A-time; DoE: Design of experiment; ANOVA: Analysis of variance; PRESS: Predicted residual error sum of squares; SU-INS: 6XHis-SUMO tag-Lispro proinsulin construct; FFD: Fractional factorial design; CCRD: Central composite rotatable
}

design; BBD: Box-Behenken design; CCFD: Central composite face-entered design; OM-l: Optimized media-l; IPTG: Isopropyl $\beta$-d-1-thiogalactopyranoside; OD: Optical density; PMSF: Phenylmethylsulfonyl fluoride; POI: Protein of interest; SDS-PAGE: Sodium dodecyl sulfate-polyacrylamide gel electrophoresis; LB: Luria-Bertani; psi: Pounds per square inch; DO: Dissolved oxygen; RPM: Revolutions per minute; WM: Volume of air per unit of medium per unit of time; CDW: Cell dry weight.

\section{Supplementary Information}

The online version contains supplementary material available at https://doi. org/10.1186/s12896-021-00732-4.

Additional file 1: Figure S1. Original Figure 8A. POI soluble expression and Purification. Coomassie stained 12\% SDS-PAGE: POI soluble expression in LB and OM-I media. M. Protein Marker. 1-3: POI soluble expression in LB media. 4-6: POI soluble expression in OM-I media. Figure S2. Original Figure 8B. POI soluble expression and Purification. Coomassie stained 12\% SDS-PAGE: SU-INS POI IMAC purification. M. Protein Ladder.1: Cell lysate supernatant (Unpurified), 2: Purified POI. Figure S2. Original Figure 9B. SU-INS POI soluble expression in fermentor. Coomassie stained 12\% SDSPAGE: M. Protein Ladder.1: Post-induction cell lysate supernatants

\section{Acknowledgements}

The authors would like to express their sincere gratitude to PersisGen Par accelerator and National Institute of Genetic Engineering and Biotechnology for providing access to required instruments and financial support.

\section{Authors' contributions}

All authors conceived and planned the study. Experiments were carried out by ABK. Analyses were performed by ABK, SA, MHS and FM. The first draft of the manuscript was written by $A B K$ and all authors commented on previous versions of the manuscript. All authors read and approved the final manuscript.

\section{Funding}

This study was financially supported by PersisGen Par accelerator, Tehran, Iran, and National Institute of Genetic Engineering and Biotechnology, Tehran, Iran.

Availability of data and materials

The datasets supporting the conclusions of this article are included within the article.

\section{Declarations}

Ethics approval and consent to participate

This article does not contain any studies with human participants or animals performed by any of the authors.

\section{Consent for publication}

The authors provide consent for publication.

\section{Competing interests}

The authors declare no competing interests.

\section{Author details}

${ }^{1}$ Bioprocess Engineering Group, Institute of Industrial and Environmental Biotechnology, National Institute of Genetic Engineering and Biotechnology (NIGEB), Tehran, Iran. ${ }^{2}$ Medical Genetics Group, Institute of Medical Biotechnology, National Institute of Genetic Engineering and Biotechnology (NIGEB), Tehran, Iran. ${ }^{3}$ Biotechnology Research Center, Pasteur Institute of Iran, Tehran, Iran.

Received: 5 May 2021 Accepted: 22 December 2021

Published online: 03 January 2022 


\section{References}

1. Franzè S, Cilurzo F, Minghetti P. Insulin biosimilars: the impact on rapidacting analogue-based therapy. BioDrugs. 2015;29(2):113-21. https://doi. org/10.1007/s40259-015-0121-x.

2. Walsh $\mathrm{G}$. Therapeutic insulins and their large-scale manufacture. Appl Microbiol Biotechnol. 2005;67(2):151-9.

3. Noble SL, Johnston E, Walton B. Insulin lispro: a fast-acting insulin analog. Am Fam Physician. 1998;57(2):279-86, 289-92.

4. Chance R, Glazer N, Wishner K. Insulin Lispro (Humalog). In 1999, p. 149-71.

5. Baeshen MN, BoubackTAF, Alzubaidi MA, Bora RS, Alotaibi MAT, Alabbas OTO, et al. Expression and purification of C-Peptide containing insulin using pichia pastoris expression system. Biomed Res Int. 2016:2016:3423685

6. Costa S, Almeida A, Castro A, Domingues L. Fusion tags for protein solubility, purification and immunogenicity in Escherichia coli: the novel Fh8 system. Front Microbiol. 2014;5:63. https://doi.org/10.3389/fmicb.2014. 00063.

7. Rosano GL, Ceccarelli EA. Recombinant protein expression in Escherichia coli: advances and challenges. Front Microbiol. 2014;5:172. https://doi. org/10.3389/fmicb.2014.00172.

8. Lobstein J, Emrich CA, Jeans C, Faulkner M, Riggs P, Berkmen M. SHuffle, a novel Escherichia coli protein expression strain capable of correctly folding disulfide bonded proteins in its cytoplasm. Microb Cell Fact. 2012;11(1):753. https://doi.org/10.1186/1475-2859-11-56

9. Nikerel IE, Öner E, Kirdar B, Yildirim R. Optimization of medium composition for biomass production of recombinant Escherichia coli cells using response surface methodology. Biochem Eng J. 2006;32(1):1-6.

10. Kusuma SAF, Parwati I, Rostinawati T, Yusuf M, Fadhlillah M, Ahyudanari RR, et al. Optimization of culture conditions for Mpt64 synthetic gene expression in Escherichia coli BL21 (DE3) using surface response methodology. Heliyon. 2019;5(11):e02741.

11. Abu ML, Nooh HM, Oslan SN, Salleh AB. Optimization of physical conditions for the production of thermostable T1 lipase in Pichia guilliermondii strain SO using response surface methodology. BMC Biotechnol. 2017;17(1):78. https://doi.org/10.1186/s12896-017-0397-7.

12. Papaneophytou CP, Kontopidis G. Statistical approaches to maximize recombinant protein expression in Escherichia coli: a general review. Protein Expr Purif. 2014;94:22-32.

13. Aida Bakhshi Khalilvand, Saeed Aminzadeh, Mohammad Hossein Sanati FM. Cytoplasmic soluble Lispro insulin production in Escherichia coli, product yield optimization and physiochemical characterization (submitted for publication). 2021.

14. Wang Y, Li Y-Z. Cultivation to improve in vivo solubility of overexpressed arginine deiminases in Escherichia coli and the enzyme characteristics. BMC Biotechnol. 2014;14(1):53. https://doi.org/10.1186/1472-6750-14-53.

15. Baeshen MN, Al-Hejin AM, Bora RS, Ahmed MMM, Ramadan HAl, Saini $\mathrm{KS}$, et al. Production of biopharmaceuticals in E. coli: current scenario and future perspectives. J Microbiol Biotechnol. 2015:25(7):953-62.

16. Packiam KAR, Ramanan RN, Ooi CW, Krishnaswamy L, Tey BT. Stepwise optimization of recombinant protein production in Escherichia coli utilizing computational and experimental approaches. Appl Microbiol Biotechnol. 2020;104(8):3253-66. https://doi.org/10.1007/ s00253-020-10454-w.

17. Elibol M. Optimization of medium composition for actinorhodin production by streptomyces coelicolor A3(2) with response surface methodology. Process Biochem. 2004;39:1057-62.

18. Sunitha K, Lee J-K, Oh T-K. Optimization of medium components for phytase production by E. coli using response surface methodology. Bioprocess Eng. 1999;21(6):477-81. https://doi.org/10.1007/PL00009086.

19. Kenari SLD, Alemzadeh I, Maghsodi V. Production of I-asparaginase from Escherichia coli ATCC 11303: optimization by response surface methodology. Food Bioprod Process. 2011;89(4):315-21.

20. Ghoshoon MB, Berenjian A, Hemmati S, Dabbagh F, Karimi Z, Negahdaripour $M$, et al. Extracellular production of recombinant I-asparaginase II in Escherichia coli: medium optimization using response surface methodology. Int J Pept Res Ther. 2015;21(4):487-95. https://doi.org/10.1007/ s10989-015-9476-6.

21. Dehnavi E, Aghaeepoor M, Kobarfard F, Akbari Eidgahi M, Shabani A, Ahmadi M, et al. Optimization of culture media for extracellular expression of streptokinase in Escherichia coli using response surface methodology in combination with Plackett-Burman design. Trop J Pharm Res. 2017;16:2567-76.

22. Shahbazmohammadi $\mathrm{H}$, Omidinia E. Medium optimization for improved production of dihydrolipohyl dehydrogenase from bacillus sphaericus PAD-91 in Escherichia coli. Mol Biotechnol. 2017;59(7):260-70. https://doi. org/10.1007/s12033-017-0013-z.

23. Long J, Zhao X, Liang F, Liu N, Sun Y, Xi Y. Optimization of fermentation conditions for an Escherichia coli strain engineered using the response surface method to produce a novel therapeutic DNA vaccine for rheumatoid arthritis. J Biol Eng. 2018;12(1):22. https://doi.org/10.1186/ s13036-018-0110-y.

24. Zhou H-Y, Wu W-J, Niu K, Xu Y-Y, Liu Z-Q, Zheng Y-G. Enhanced L-methionine production by genetically engineered Escherichia coli through fermentation optimization. 3 Biotech. 2019;9(3):96. https://doi.org/10. 1007/s13205-019-1609-8.

25. Zare H, Mir Mohammad Sadeghi H, Akbari V. Optimization of fermentation conditions for reteplase expression by Escherichia coli using response surface methodology. Avicenna J Med Biotechnol. 2019;11(2):162-8.

26. Han HM, Kim IJ, Yun EJ, Lee JW, Cho Y, Jin Y-S, et al. Overproduction of exopolysaccharide colanic acid by Escherichia coli by strain engineering and media optimization. Appl Biochem Biotechnol. 2021;193(1):111-27. https://doi.org/10.1007/s12010-020-03409-4.

27. Duan M, Wang Y, Yang G, Li J, Wan Y, Deng Y, et al. High-level production of $\gamma$-cyclodextrin glycosyltransferase in recombinant Escherichia coli BL21 (DE3): culture medium optimization, enzymatic properties characterization, and product specificity analysis. Ann Microbiol. 2020;70(1):70. https://doi.org/10.1186/s13213-020-01610-8.

28. Ukkonen K, Vasala A, Ojamo H, Neubauer P. High-yield production of biologically active recombinant protein in shake flask culture by combination of enzyme-based glucose delivery and increased oxygen transfer. Microb Cell Fact. 2011;10(1):107. https://doi.org/10.1186/ 1475-2859-10-107.

29. Wang $H$, Wang F, Wei D. Impact of oxygen supply on rtPA expression in Escherichia coli BL21 (DE3): ammonia effects. Appl Microbiol Biotechnol. 2009;82(2):249-59.

30. Striedner G, Cserjan-Puschmann M, Pötschacher F, Bayer K. Tuning the transcription rate of recombinant protein in strong Escherichia coli expression systems through repressor titration. Biotechnol Prog. 2003;19(5):1427-32

\section{Publisher's Note}

Springer Nature remains neutral with regard to jurisdictional claims in published maps and institutional affiliations.

Ready to submit your research? Choose BMC and benefit from

- fast, convenient online submission

- thorough peer review by experienced researchers in your field

- rapid publication on acceptance

- support for research data, including large and complex data types

- gold Open Access which fosters wider collaboration and increased citations

- maximum visibility for your research: over $100 \mathrm{M}$ website views per year

At BMC, research is always in progress.

Learn more biomedcentral.com/submissions 